\title{
Effects of phosphate-solubilizing bacteria, native microorganisms, and rock dust on Jatropha curcas L. growth
}

\author{
E.B. Santana ${ }^{1}$, E.L.S. Marques $^{2}$ and J.C.T. Dias ${ }^{2}$ \\ ${ }^{1}$ Departamento de Ciências Exatas e da Natureza, \\ Universidade do Estado da Bahia, Alagoinhas, BA, Brasil \\ ${ }^{2}$ Departamento de Ciências Biológicas, \\ Universidade Estadual de Santa Cruz, Ilhéus, BA, Brasil \\ Corresponding author: E.B. Santana \\ E-mail: emanuelkantt@gmail.com
}

Genet. Mol. Res. 15 (4): gmr. 15048729

Received April 25, 2016

Accepted June 9, 2016

Published October 5, 2016

DOI http://dx.doi.org/10.4238/gmr.15048729

Copyright (C) 2016 The Authors. This is an open-access article distributed under the terms of the Creative Commons Attribution ShareAlike (CC BY-SA) 4.0 License.

\begin{abstract}
Microorganisms with the ability to release nutrients to the soil from insoluble sources may be useful for plant cultivation. We evaluated the growth-promoting effect on Jatropha curcas L. of phosphate-solubilizing bacteria (PSB) and the native microbiota in soil with or without rock dust. J. curcas L. is important for biodiesel production. The experiments were performed in a greenhouse under a random-statistical design with 14 replicates. The soil received increasing dosages of rock dust. The presence of resident microorganisms and PSB inoculum was correlated with plant height, biomass production, and phosphorus content in plants for 120 days. Native soil microorganisms were detected and identified using denaturing gradient gel electrophoresis and DNA sequence analysis. Several bacterial populations belonged to the genus
\end{abstract}


Bacillus. Populations associated with the phyla Chytridiomycota and Ascomycota were detected among the fungi. The best results for the variable plant height were correlated with the presence of resident microbiota and rock dust until the end of the experiment. The largest biomass production and the highest content of phosphorus occurred in the presence of soil-resident microbiota only up to 120 days. No significant effects were observed for biomass production with the use of PSB combined with rock dust. J. curcas L. under the influence of only resident microbiota showed the best plant growth results. Future research will focus on the specificity of resident microbiota activity in plant growth promotion and the isolation of these microorganisms to produce a new inoculum to be tested in various plants.

Key words: Jatropha curcas L.; Phosphate-solubilizing bacteria; Rock dust; Denaturing gradient gel electrophoresis; Sequencing analysis

\section{INTRODUCTION}

Purging nut (Jatropha curcas L.) is native to Central America. It is suitable for agrofuel production in tropical and subtropical regions because it is able to adapt to diverse pedoclimatic conditions (including semi-arid conditions) and has low nutritional demands. $J$. curcas L. is considered a rustic crop and is adapted to most soil conditions, but it thrives in soils of low natural fertility (de Arruda et al., 2004; Dias, 2007; Freitas et al., 2011; Dias et al., 2012). Almost all parts of the plant contain a cocktail of toxic and anti-nutritional compounds (e.g., alkaloids, terpenoids, tannins, and trypsin inhibitors), with phorbol ester and curcin among other toxic phytochemicals. The plant's latex inhibits growth in various strains of bacteria and fungi. Because it is not yet considered a domesticated plant, J. curcas L. is the subject of management and cultivation studies.

The crop yield of $J$. curcas L. may be enhanced by employing microorganisms that improve plant growth, once they have demonstrated functional properties in the soil. Such microbes are designated "plant growth-promoting microorganisms" and constitute a heterogeneous group that may be found in the rhizosphere, at the surface of the soil, or in association with roots; they may improve the quality or extent of plant growth in a direct or indirect fashion (Ahmad et al., 2008). Microbial strategies include the production of plant hormones, such as auxins, gibberellins, cytokinins, or polyamides (Tsavkelova et al., 2005), and participation in important transformations within the carbon $(\mathrm{C})$ and nitrogen $(\mathrm{N})$ cycle. Some bacteria also promote plant growth indirectly by producing siderophores. This mode of action occurs by a mechanism of competition, whereby bacteria capture available iron in the soil, reducing its availability to certain pathogenic fungi, thus restricting the proliferation of the fungi (O'Sullivan and O'Gara, 1992). Phytopathogenic fungi cannot develop and multiply within an iron-deficient rhizosphere.

Another mechanism that may influence plant growth is the production of exopolysaccharides (EPSs) by bacteria associated with the plant's radicular system. EPSs are extracellular polysaccharides produced by microorganisms such as fungi and bacteria that adhere to cellular surfaces or are externally excreted into the medium (Seesuriyachan et al., 2012). Production of EPSs arising from plant-microorganism interactions may lead

Genetics and Molecular Research 15 (4): gmr.15048729 
to the formation of a biofilm. Biofilms limit the diffusion of compounds secreted by roots and bacteria, allowing better adherence and colonization of surfaces where nutrients gather. They also contribute to nutrient and mineral fixation and water retention, and protect the plant against environmental stresses such as dehydration, salinity, and temperature variation (Santos and Esposito, 2014). Nevertheless, plant growth-promoting bacteria may induce chemical and physical modifications in plants, resulting in an increase of tolerance to these stresses (Yang et al., 2009). Plant growth-promoting bacteria that are associated with plant roots increase such tolerance by stimulating radicular proliferation, i.e., enhanced production of lateral roots and root hairs (Paul and Lade, 2014), which improves water acquisition and nutrient absorption. Finally, microorganisms may also improve the nutritional status of the plant by solubilizing phosphorus $(\mathrm{P})$. Phosphorus is the most limiting nutrient in agricultural production, especially in tropical regions, owing to its low availability within the soil (Khan et al., 2010).

The use of phosphate-solubilizing microorganisms (PSMs) associated with a lowsolubility phosphorous source, such as in natural rocks, has been successful in various crops, resulting in improvements in growth and production (Rodríguez and Fraga, 1999). Natural rocks are milled to produce a dust, which provides a source of nutrients for plant cultivation, and may also adjust soil chemistry factors such as acidity (Lapido-Loureiro and Nascimento, 2009). Owing to the indiscriminate application and excessive use of phosphate fertilizers, which may have negative effects on agricultural sustainability and the safety of the soil and environment, rock dust constitutes a natural alternative for farmers; it ensures competitive production while preserving nutrient reserves in the soil. The nutrients in rock dust are solubilized by the organic acids produced by soil microorganisms. Among these bio-solubilizing microorganisms, certain fungal genera (Flavobacterium, Penicillium, Aspergillus, and Solerotium) and bacterial genera (Bacillus, Pseudomonas, Mycobacterium, and Micrococcus) are noteworthy. Organic acids produced by the PSMs fulfill an important role in the dissolution, transport, and concentration of elements on the Earth's surface, as well as in soil formation and plant nutrition, owing to the establishment of soluble complexes originating in mineral rocks (Kpomblekou-A and Tabatabai, 2003). In addition to bio-solubilization by organic acids, these microorganisms may be responsible for the mineralization of phosphorus (Vassileva et al., 2010). By producing phosphatases, the soil microbial biomass hydrolyses various forms of organic phosphorus formed or stored in the soil, thereby releasing inorganic phosphorus that will be immobilized by plants and microorganisms. Intrinsic characteristics of the PSMs within each type of soil determine the structural and functional equilibrium; those characteristics are physical (porosity, stability, and structure), chemical ( $\mathrm{pH}$ and nutrient content), and biological (interactions with the native plant microbiota) (Grayston et al., 2004). Such factors determine the success or failure of the use of microorganisms to promote plant growth. Plants exert different effects on the fungi (Broz et al., 2007) and bacteria (Marchante et al., 2008) of the soil microbiota that may reflect the profusion and/or diversity of the microorganisms.

The objective of this study was to evaluate the growth-promoting effect of phosphatesolubilizing bacteria (PSB) and native microbiota on J. curcas L. in soil with or without the addition of rock dust. This is new, previously unpublished research on the development of plants under such conditions. The use of rock dust in the presence of PSMs and the isolation of native microorganisms that promote plant growth may improve the cultivation of $J$. curcas L. and possibly that of other plants.

Genetics and Molecular Research 15 (4): gmr.15048729 


\section{MATERIAL AND METHODS}

\section{Soil and rock dust}

The soil used in the experiment was collected at depths of up to $10 \mathrm{~cm}$ within a preservation area at the Experimental Unit of the Agrarian Development Company of Bahia (EBDA), located at coordinates $12^{\circ} 10^{\prime} 26^{\prime \prime}$ South (S) and $38^{\circ} 26^{\prime} 15^{\prime \prime}$ West (W). The soil was triple-sampled, conditioned in labeled bags, and characterized at the EBDA soil laboratory, in Salvador, Bahia, Brazil. Rock dust added to the soil was provided by the Sao Francisco Mining Company, located in the São José's District, in the county of Feira de Santana, Bahia, Brazil, and was chemically characterized from triple samples at the EBDA soil laboratory. The rock dust used for soil preparation included reject ore, but the main part comprised granite. The granulometric analysis was carried out at the Civil Engineering Laboratory, CEPED, University of the State of Bahia (UNEB), Camaçari, Bahia, Brazil.

\section{Soil conditioning and fertilization}

Soil was sifted in a $5-\mathrm{mm}$ mesh sieve before weighing $(18 \mathrm{~kg} / \mathrm{pot})$, then fertilized with variable dosages of rock dust 1 month before planting, based on the volume of a truncated cone formula: $\mathrm{V}=1 / 3 \times \pi \times \mathrm{h}\left(\mathrm{R}^{2}+\mathrm{Rr}+\mathrm{r}^{2}\right)$, where $R$ is the radius of the pot's base circle, $r$ is the radius of the pot's top circle, and $h$ is the pot's height. Dosages of rock dust were added to the soil aliquots, which were organized on a resistant canvas and mixed using a shovel and rake. No other fertilizers were used, with the exception of urea at 30 and 60 days after planting. The urea dosage for all pots corresponded to $40 \mathrm{~kg} / \mathrm{ha}$, with $1.17 \mathrm{~g}$ added to each pot.

\section{Seed inoculation, planting and irrigation}

All seeds used in the experiment were provided by the Agrarian Development Company of Bahia (EBDA). From a total of 520 seeds disinfected with 3\% sodium hypochlorite, half were inoculated in a sterilized cabinet with PSB at a concentration of $10^{8}$ cells per $\mathrm{mL}$, by means of dipping in sterilized water containing $0.1 \%$ xanthan gum for $10 \mathrm{~min}$. The bacteria used for inoculation had previously been isolated, identified by sequencing, and selected in National Botanical Research Institute phosphate (NBRIP) medium containing 10

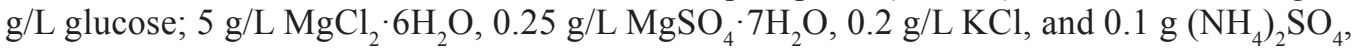
supplemented with $\mathrm{Ca}_{3} \mathrm{PO}_{4}$, to a final concentration of $1000 \mathrm{mg}$ phosphorus per liter in solid medium and $100 \mathrm{mg}$ phosphorus per liter in liquid medium (Nautiyal, 1999). Different values of initial $\mathrm{pH}$ were established: 5.0, 6.0, and 7.0. The inoculum comprised four Grampositive rhizosphere bacteria from the Bacillus genera: Bacillus atrophaeus MM20 (R2), B. atrophaeus SL44 (R11), B. atrophaeus SL13 (R35), and Bacillus vallismortis (S17), which were donated by the Environmental Monitoring Laboratory of the State University of Santa Cruz, Ilhéus, Bahia, Brazil. During sowing, three seeds were planted per pot at a depth of $5 \mathrm{~cm}$, inserted with the caruncle uppermost. Thinning was performed 15 days after emergence, removing seedlings considered less vigorous and leaving only one plant per pot to ensure a uniform size of seedlings. Irrigation was performed daily in the pots when required to restore water consumed by evapotranspiration and to maintain soil humidity at approximately field capacity.

Genetics and Molecular Research 15 (4): gmr.15048729 


\section{Experimental design}

The analysis of $J$. curcas L. growth was performed in a greenhouse. Ten treatments were established with consideration for the soil collected, the dosages of rock dust, and the inoculation of seeds with bacteria. The treatments were set in a completely randomized design, with 14 replicates, being 5 dosages of rock dust in the presence or absence of inoculum. The rock dust dosages were $0,13.5,27,54$, and $81 \mathrm{~g} /$ pot. Plants for the analysis of only native microbiota (SWRWI) were characterized by the absence of inoculum in the seed and the absence of rock dust; S135RWI to S81RWI had increasing dosages of rock dust, described previously, without inoculation. Plants from S135RI to S81RI had the same increasing dosages of rock dust, with inoculation. Plants from SWRI were inoculated but not supplied with rock dust.

\section{Control of pests and weeds}

Pest control during the experiment was achieved by periodical sampling to evaluate damage and adopt the most efficient control method. A systemic and contact acaricide from the chemical group avermectin was used at dosages of $2 \mathrm{~mL} / \mathrm{L}$ water to control white and red mites, applied with a manual backpack-type sprayer. Weeds were manually ripped out as they emerged.

\section{Soil DNA extraction, polymerase chain reaction (PCR), denaturing gradient gel electrophoresis (DGGE), and sequencing analysis}

DNA extraction and DGGE to determine the profile of the soil microbial community were carried out at the Laboratory of Microbiology and Biotechnology at the State University of Santa Cruz (UESC), Ilhéus, Bahia, Brazil. Soil samples for DNA extraction, amplification, and DGGE were obtained at zero (SWRWI*), 120 (SWRWI), and 210 (SWRWI') days into the experiment in triplicate. The remaining samples were obtained at 120 and 210 days (marked with an apostrophe) with three replicates, and conditioned in labeled plastic containers. The total DNA (300 mg) was extracted from soil samples using a Powersoil DNA kit (MO BIO Laboratories), following the manufacturer instructions. The DNA was analyzed by electrophoresis on $1 \%(\mathrm{w} / \mathrm{v})$ agarose gel, stained with SYBR Green, and visualized and digitized using a transilluminator with a Kodak camera attached. The DNA was amplified using primers for the region V6-V8 of the rDNA gene 984F with a GC clamp, 5'-AACGCGAAGAACCTTAC-3', and 1378R 5'-CGGTGTGTACAAGGCCCGGGAACG-3' (Heuer and Smala, 1997). The GC clamp was used to prevent the complete denaturation of the amplified products (Muyzer et al., 1993). All PCRs used a mix containing 1.25 L Taq DNA polymerase (Invitrogen), $5 \mathrm{~mL}$ reaction buffer 10X, $200 \mu \mathrm{M}$ deoxyribonucleotides, $\mathrm{MgCl}_{2} 3.0 \mathrm{mM}, 1 \mu \mathrm{L}$ DNA, and sterilized Milli-Q water, to make a final volume of $25 \mu \mathrm{L}$. An automatic thermocycler (Eppendorf Personal Mastercycler) was used for amplification. Gene sequences of the amplified rDNA were analyzed on $8 \%$ polyacrylamide gel $(\mathrm{w} / \mathrm{v})$ at 37.5:1 (acrylamide:bisacrylamide) with a denaturing gradient of $30-60 \%$. The gels were electrophoresed in buffer TAE 1X (acetate $20 \mathrm{mM}$ Tris, $\mathrm{pH} 7.4$, sodium acetate $10 \mathrm{mM}, 0.5 \mathrm{mM}$ disodium ethylenediaminetetraacetic acid (EDTA) at a constant voltage of $70 \mathrm{~V}$ for $15 \mathrm{~min}$ at $60^{\circ} \mathrm{C}$, and $200 \mathrm{~V}$ for $4 \mathrm{~h}$ at $60^{\circ} \mathrm{C}$. The gels were stained with silver nitrate and developed with sodium hydroxide. Each band was considered an operational taxonomic unit (OTU). Band patterns on the gel were used to

Genetics and Molecular Research 15 (4): gmr.15048729 
construct a binary matrix, with values of 1 for presence and 0 for absence of bands of a particular size. The similarity matrix was calculated using Jaccard's coefficient (Legendre and Legendre, 1983), and the dendrograms were constructed using the UPGMA algorithm and the Free-Tree software. Relevant bands were excised from the DGGE for sequencing. Sample sequencing was performed at ACTGene Molecular Analysis Ltd. (Biotechnology Center, UFRGS, Porto Alegre, RS, Brazil) using an AB 3500 Genetic Analyzer automatic sequencer equipped with $50 \mathrm{~cm}$ capillaries and POP7 polymer (Applied Biosystems). DNA frames (60 ng) were labeled using 4.5 pmol primer 1378R 5'-CGGTGTGTACAAGGCCCGGGAACG-3', 0.5 mL Big Dye Terminator v3.1 Cycle Sequencing Kit standard reagent (Applied Biosystems), to a final volume of $10 \mu \mathrm{L}$. Labeling reactions were carried out in a LGC XP Thermal Cycler, with an initial denaturation at $96^{\circ} \mathrm{C}$ for 3 min followed by 25 cycles at $96^{\circ} \mathrm{C}$ for $10 \mathrm{~s}, 55^{\circ} \mathrm{C}$ for $5 \mathrm{~s}$, and $60^{\circ} \mathrm{C}$ for $4 \mathrm{~min}$. Once labeled, samples were purified by precipitation with $75 \%$ isopropyl alcohol and washed with $60 \%$ ethyl alcohol. The precipitated products were diluted in $10 \mu \mathrm{L}$ methylamide $\mathrm{Hi}-\mathrm{Fi}$ (Applied Biosystems), denatured at $95^{\circ} \mathrm{C}$ for $5 \mathrm{~min}$, cooled in ice for $5 \mathrm{~min}$, and electroinjected into an automatic sequencer. Sequencing data were collected using the Data Collection 2 software (Applied Biosystems), with the following parameters: Dye Set Z; Mobility File KB 3500_POP7_BDTv3.mob; BioLIMS Project 3500_Project1; Run Module 1FastSeq50 POP7_50cm_cfv_100; and Analysis Module 1 BC-3500SR_Seq_FASTA.sa. Sequences were submitted to BLASTn at the National Center for Biotechnology Information (NCBI) to identify microorganisms (Altschul et al., 1990).

\section{Statistical analysis}

All plant height, biomass production, and nutrient content data for the plants were investigated using analysis of variance and the Tukey test $(\mathrm{P}<0.01)$, with the aid of the Biostat software.

\section{RESULTS}

\section{Soil analysis}

The soil used in the experiment was classified as a grayish sandy acrisol (Hapludalf), acidic (Table 1), modest in organic matter content and with low phosphorus content (Table 2). The soil received rock dust rejected from a quarry where the main product was gravel. This mining reject comprised a mixture of dust from different rock layers. The majority of the material originated from granite. Chemical analysis of the rock dust revealed the presence of calcium $(\mathrm{Ca})$, magnesium $(\mathrm{MgO})$, potassium $\left(\mathrm{K}_{2} \mathrm{O}\right)$, and phosphorus $\left(\mathrm{P}_{2} \mathrm{O}_{5}\right)$. The rock dust had higher nutrient and $\mathrm{pH}$ values than the native soil, especially with regards to phosphorus. The content of phosphorus in the rock dust was $247 \mathrm{mg} / \mathrm{dm}^{3}$ and the $\mathrm{pH}$ was 6.6 (Table 3). Among the particles in the rock dust, $89.9 \%$ had a size under $0.15 \mathrm{~mm}$ (Table 4). Treatments are shown in Table 5.

\begin{tabular}{|c|c|c|c|c|c|c|c|}
\hline \multicolumn{3}{|c|}{ Density $\left(\mathrm{g} / \mathrm{cm}^{3}\right)$} & \multicolumn{5}{|c|}{ Granulometry (\%) } \\
\hline Apparent & Real & Clay & Silt & Sand & Humidity & $\mathrm{MO}$ & Classification \\
\hline 1.22 & 2.34 & 8.2 & 0.3 & 90.5 & 0.3 & 0.7 & Sandy loam \\
\hline
\end{tabular}

Analysis performed at the Soil Laboratory, EBDA, Salvador, Bahia, 2011.

Genetics and Molecular Research 15 (4): gmr.15048729 
Table 2. Chemical composition of the soil.

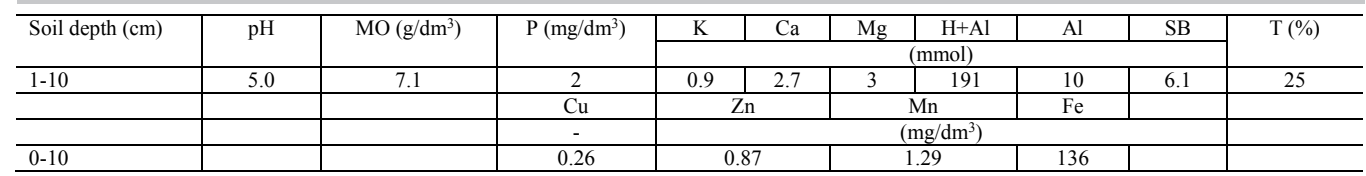

Soil Laboratory, EBDA, Salvador, Bahia.

Table 3. Chemical composition of the rock dust.

\begin{tabular}{|c|c|c|c|c|c|c|c|c|c|}
\hline \multirow[t]{2}{*}{$\mathrm{pH}$} & \multirow[t]{2}{*}{$\mathrm{MO}\left(\mathrm{g} / \mathrm{dm}^{3}\right)$} & \multirow[t]{2}{*}{$\mathrm{P}\left(\mathrm{mg} / \mathrm{dm}^{3}\right)$} & $\mathrm{K}$ & $\mathrm{Ca}$ & $\mathrm{Mg}$ & $\mathrm{H}+\mathrm{Al}$ & $\mathrm{Al}$ & SB & \multirow[t]{2}{*}{$\mathrm{T}(\%)$} \\
\hline & & & \multicolumn{6}{|c|}{$(\mathrm{mmol})$} & \\
\hline \multirow[t]{4}{*}{6.6} & 4.58 & 247 & 5.1 & 3.57 & 4 & 0.00 & 0.05 & 3.10 & 5.07 \\
\hline & & $\mathrm{Cu}$ & \multicolumn{2}{|c|}{$\mathrm{Zn}$} & \multicolumn{2}{|c|}{$\mathrm{Mn}$} & $\mathrm{Fe}$ & & \\
\hline & & - & \multicolumn{5}{|c|}{$\left(\mathrm{mg} / \mathrm{dm}^{3}\right)$} & & \\
\hline & & 0.58 & \multicolumn{2}{|c|}{0.9} & \multicolumn{2}{|c|}{1.4} & 158 & & \\
\hline
\end{tabular}

Soil Laboratory, EBDA, Salvador, Bahia.

Table 4. Rock dust granulometry.
\begin{tabular}{l|c|c}
\hline Sieves (mm) & Unfiltered dust granules (\%) & Filtered dust granules (\%) \\
\hline 1.2 & 25.1 & 84.9 \\
\hline 0.6 & 18.8 & 81.2 \\
\hline 0.3 & 10.9 & 89.9 \\
\hline 0.15 & 10.1 & \\
\hline
\end{tabular}

Analyzed by the Civil Engineering Laboratory - CEPED, UNEB.

Table 5. Treatments used in the experiment.

\begin{tabular}{l|l}
\hline Treatment & Characteristics \\
\hline SWRWI & Soil without rock dust, without inoculum \\
\hline S135RWI & Soil with 13.5 g rock dust, without inoculum \\
\hline S27RWI & Soil with 27 g rock dust, without inoculum \\
\hline S54RWI & Soil with 54 g rock dust, without inoculum \\
\hline S81RWI & Soil with 81 g rock dust, without inoculum \\
\hline SWRI & Soil without rock dust, with inoculum \\
\hline S135RI & Soil with 13.5 g rock dust, with inoculum \\
\hline S27RI & Soil with 27 g rock dust, with inoculum \\
\hline S54RI & Soil with 54 g rock dust, with inoculum \\
\hline S81RI & Soil with 81 g rock dust, with inoculum \\
\hline
\end{tabular}

\section{Plant height and dry biomass}

Treatments S135RWI and S27RWI (Figure 1), characterized by the absence of inoculant and the presence of rock dust, produced the best results in terms of plant height for $J$. curcas L., despite a non-significant effect observed at the end of the experiment. Dosages of 13.5 and $27 \mathrm{~g}$ corresponded to an average of 21.15 and $20.70 \mathrm{~cm}$, respectively. These treatments produced better results than SWRWI, which was under the influence of native microbiota only (Figure 2). However, the results from S135RWI and S27RWI were not completely satisfactory; despite better results for plant height they did not result in a greater

Genetics and Molecular Research 15 (4): gmr.15048729 
increase of biomass. Plants of the remaining samples, with dosages of rock dust higher than 13.5 and $27 \mathrm{~g}$, did not show growth over the values observed for plants of SWRWI in the initial period of the experiment.
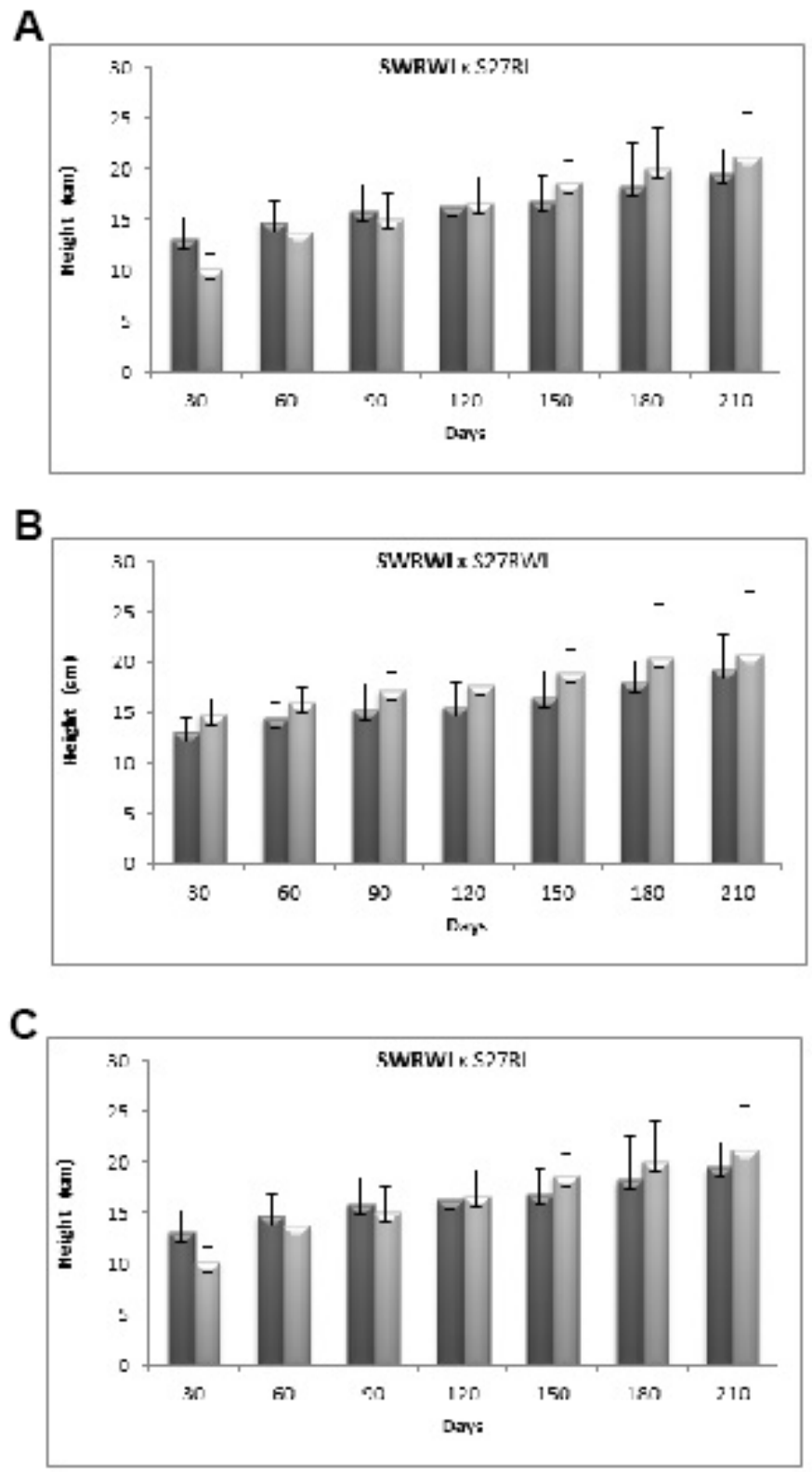

Figure 1. Contrast between the average plant height in treatments (A) SWRWI ( 0 g rock dust, non-inoculated $)$ and S135RWI (13.5 g rock dust, non-inoculated), (B) SWRWI x S27RWI (27 g rock dust, non-inoculated), and (C) SWRWI x S54RI (54 g rock dust, inoculated).

Genetics and Molecular Research 15 (4): gmr.15048729 

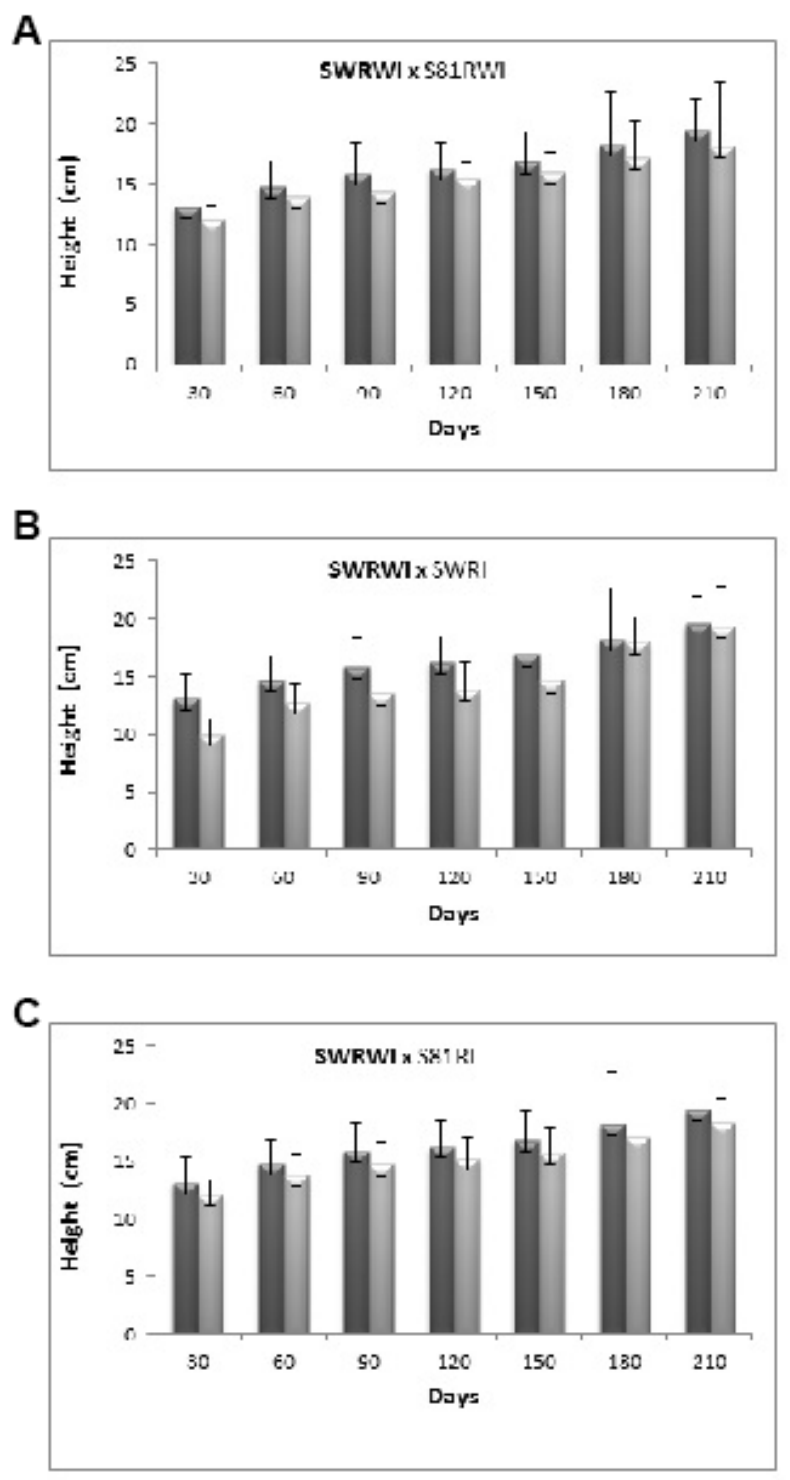

Figure 2. Contrast between the average plant height in treatments (A) SWRWI ( $0 \mathrm{~g}$ rock dust, non-inoculated) and S81RWI (81 g rock dust, non-inoculated), (B) SWRWI x SWRI (0 g rock dust, inoculated), and (C) SWRWI x S81RI (81 g rock dust, inoculated).

Considering the plant's dry biomass, the production was higher in treatments under the influence of native microbiota only, with a significant statistical effect when compared with the other treatments (Table 6). Plants from SWRWI produced averages of 70.54, 73.98, and $102.76 \mathrm{~g}$ of dry mass from leaves, roots, and stalks, respectively. These values were $17.33,22.6$, and $6.16 \%$ higher than in SWRI, the second treatment with the best dry biomass production, characterized by the presence of inoculum without rock dust. 
Table 6. Dry mass from leaves, roots, and stalks of purging nut, after an experimental period of 210 days, control treatment (T1), treatments including rock dust, inoculated treatments, and both.

\begin{tabular}{l|c|c|c}
\hline Treatment & \multicolumn{3}{|c}{ Mean weight of plant parts $(\mathrm{g})$} \\
\hline T1 & Leaves & Roots & Stalks \\
\hline T2 & $70.54(0.27)^{\mathbf{a}}$ & $73.98(1.35)^{\mathbf{a}}$ & $102.76(3.15)^{\mathbf{a}}$ \\
\hline T3 & $40.78(0.11)$ & $46.87(1.44)$ & $60.11(2.50)$ \\
\hline T4 & $50.87(1.43)^{\mathbf{c}}$ & $48.45(1.38)$ & $97.80(1.59)^{\mathbf{b}}$ \\
\hline T5 & $41.05(1.10)$ & $55.29(1.01)$ & $78.56(3.86)$ \\
\hline T6 & $50.29(1.18)$ & $55.99(1.02)$ & $91.35(0.21)^{\mathbf{c}}$ \\
\hline T7 & $60.12(0.67)^{\mathbf{b}}$ & $60.34(0.10)^{\mathbf{b}}$ & $98.82(1.58)^{\mathbf{b}}$ \\
\hline T8 & $35.87(0.99)$ & $32.4(4.54)$ & $34.45(0.35)$ \\
\hline T9 & $41.34(0.89)$ & $40.22(1.70)$ & $41.67(0.23)$ \\
\hline T10 & $41.29(0.06)$ & $55.17(3.22)$ & $78.33(2.68)$ \\
\hline
\end{tabular}

T1-T5 refer to treatments with $0,13.5,27,54$, and $81 \mathrm{~g}$ of rock dust, without inoculation. T6-T10 refer to the same dosages of rock dust, but with inoculation. Means are followed by the standard deviation. Values followed by letters in the vertical rows are significant according to the Tukey test $(\mathrm{P}<0.01)$.

\section{DGGE analysis and DNA sequencing}

The structure of bacterial communities was transformed during the experiment, but few populations were detected by DGGE for non-inoculated as well as for inoculated treatments. Within non-inoculated treatments, using primers V6-V8 of the 16S rDNA, DGGE profiles showed that bacterial population variations also occurred over time (Figure 3A). Line SWRI* represented zero, i.e., natural soil. Two bacterial populations were detected within these samples, but were not observed after 120 days. The absence of some populations was observed after 210 days, as shown in the line for S27RWI. Three lineages were constantly present until the end of the experiment, but only in S81RWI. Bacterial lineages from the genus Bacillus were detected (Table 7).

The modification of bacterial communities after inoculation was radical (Figure 3B). There was a constant presence of the bacteria used in the inoculum. These bacteria altered the profile of the soil communities, exerting dominance during the whole experiment. The gel band corresponding to SWRWI (Figure 3A and B) features a lineage also belonging to the inoculum, indicating the presence of the bacteria before inoculation. The bacterial lineage existing before and after inoculation was identified as Bacillus atrophaeus SL13 (Table 8). There was conspicuous variability between gel bands.

Regarding the fungal community, there were variations in the number of OTUs, analogous to the bacterial community without inoculation (Figure 3C). The population size decreased in some samples and increased in others. Plant growth in S135RWI and S27RWI was analogous to the population increment of soil fungi.

The most prominent bands within the DGGE profile for regions V6-V8 of 16S rDNA were identified by sequencing analysis of Bacillus from a rhizospheric environment and non-cultivated clones (Tables 7 and 8). For the $18 \mathrm{~S}$ rDNA, populations related to the phyla Ascomycota and Chytridiomycota were detected (Table 9). Further characteristics of plant growth are shown in the Supplementary material ( $\underline{\text { Tables } \mathbf{S 1}}, \underline{\mathbf{S 2}}$, and $\underline{\mathbf{S 3}})$.

Genetics and Molecular Research 15 (4): gmr.15048729 
A

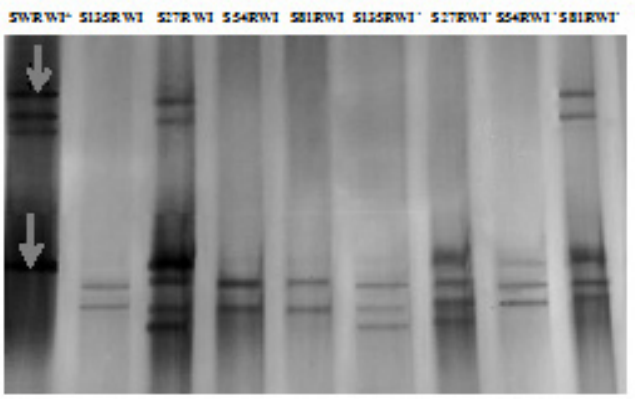

B

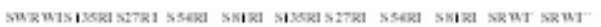

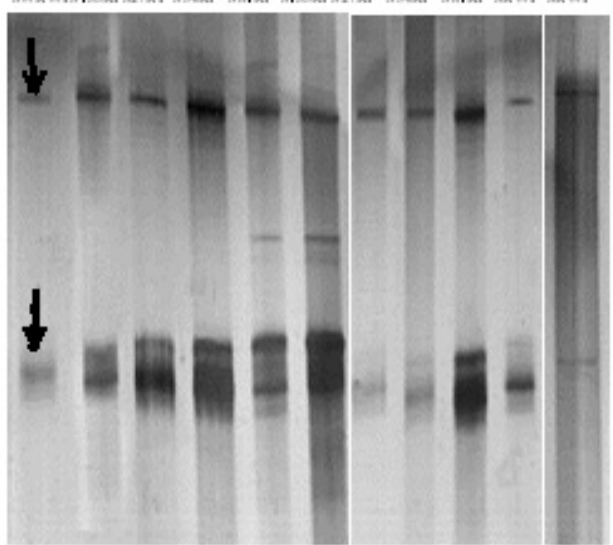

$\mathrm{C}$

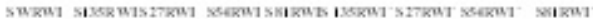

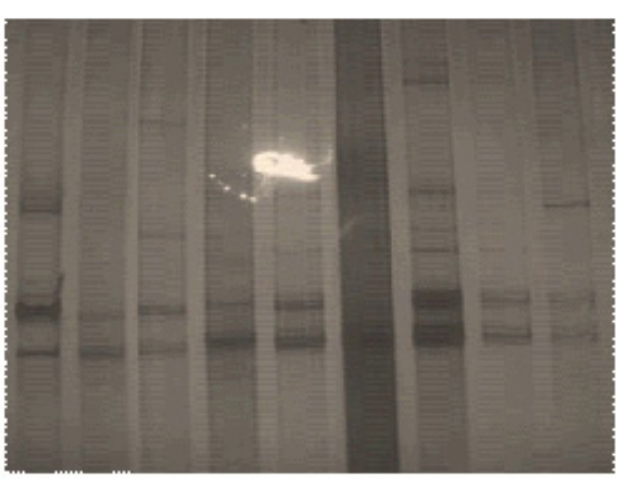

Figure 3. DGGE profiles of the region V6 of the gene 16S rDNA for treatments with inoculum (A) and without inoculum (B), using a polyacrylamide gel $8 \%$ and a denaturation gradient from 30 to $60 \%$. (C) DGGE profile obtained by the use of the primer for fungal diversity, Fung5r, using a polyacrylamide gel $8 \%$ and denaturation gradient from 0 to $50 \%$. SWRWI represents native bacterial populations, at time zero (SWRWI*) and at 210 days (SWRWI'); S135RWI-S81RWI, are treatments without inoculum, with rock dust, at 120 and 210 days (with apostrophe). S135RIS81RI, inoculum and rock dust at 120 and 210 days (with apostrophe). SWRI shows treatment with inoculum, without rock dust at 120 and 210 days (with apostrophe). Arrows show the strain of the pre-existing soil inoculum (A and B).

Genetics and Molecular Research 15 (4): gmr.15048729 
Table 7. Identification of bands obtained from the denaturing gradient gel electrophoresis (DGGE) with the primer for regions V6-V8 from the gene coding the 16S RNA using the BLASTn tool for treatments without inoculation.

\begin{tabular}{l|l|c}
\hline Band identification* & Nearest identity in GenBank (\% identity in BLASTn) - Source & Code in GenBank \\
\hline T1-1 & Non-cultivated bacterial clone (100) - Endophytic community & AJ518182 \\
\hline T3-2 & Bacillus subtilis (99) - Sediments & KF782831 \\
\hline T1-2 & Non-cultivated soil bacteria (98) - Humus layer & FR870073 \\
\hline T1-3 & Bacillus amyloliquefaciens (99) - Rhizosphere & KP100527 \\
\hline T1-4 & Bacillus atrophaeus SL13 (98) - Rhizosphere soil & FJ194959 \\
\hline T4-6 & Bacillus subtilis (100) - Rhizosphere & JX185647 \\
\hline T4-7 & Non-cultivated soil bacteria (99) - Sediments & FR870072 \\
\hline T2-8 & Bacillus vallismortis (98) - Rhizosphere & KPO52696 \\
\hline
\end{tabular}

*Numbers at the right side of the treatment designate the location of the band within the gel, from the top to the bottom. Sequences of the rDNA from microbial populations were deposited in GenBank with accession Nos. KT988308-KT988314.

Table 8. Identification of bands obtained from the denaturing gradient gel electrophoresis (DGGE) with the primer for regions V6-V8 from the gene coding the 16S RNA using the BLASTn tool for non-inoculated treatment (T1), and treatments with inoculation, at 120 and 210 days into the experiment.

\begin{tabular}{l|l|c}
\hline Band identification* & Nearest identity in GenBank (\% identity in BLASTn) - Source & Code in GenBank \\
\hline T1-1 & Non-cultivated bacterial clone (100) - Endophytic & AJ518182 \\
\hline T6-2 & Bacillus atrophaeus MM20 (97) - Rhizosphere & EU729737 \\
\hline T6-3 & Bacillus subtilis (100) - Rhizosphere & JQ361059 \\
\hline T10-4 & Bacillus atrophaeus SL13 (98) - Rhizosphere & FJ194959 \\
\hline T7-5 & Bacillus vallismortis (98) - Rhizosphere & AB021198 \\
\hline
\end{tabular}

*Numbers at the right side of the treatment designate the location of the band within the gel, from the top to the bottom. Sequences of the rDNA from microbial populations were deposited in GenBank with accession Nos. KT988308-KT98314.

Table 9. Identification of bands obtained from the denaturing gradient gel electrophoresis (DGGE) with the specific primers for fungi EF4 and Fung5r using the BLASTn tool for treatments with and without inoculation, at 120 and 210 days into the experiment.

\begin{tabular}{l|l|c}
\hline Band identification* & Nearest identity in GenBank (\% identity in BLASTn) - Source & Code in GenBank \\
\hline T4-11 & Non-cultivated eukaryotic clone (92) - Rhizosphere & JNO20201 \\
\hline T3-13 & Non-cultivated Ascomycota clone (93) - Lichen & GQ404733 \\
\hline T2-14 & Non-cultivated fungus (98) - Rhizosphere & JX846655 \\
\hline T4-15 & Non-cultivated Chytridiomycota (96) - Fungi from higher soils & GQ995333 \\
\hline T2-16 & Non-cultivated soil fungus (97) - Sediments & EF673574 \\
\hline
\end{tabular}

*Numbers at the right side of the treatment designate the location of the band within the gel, from the top to the bottom. Sequences of the rDNA from microbial populations were deposited in GenBank with accession Nos. KT988308-KT98314.

\section{DISCUSSION}

\section{Rock dust analysis}

The chemical analysis of the rock dust indicated the presence of calcium $(\mathrm{Ca})$, magnesium $(\mathrm{MgO})$, potassium $\left(\mathrm{K}_{2} \mathrm{O}\right)$, and phosphorus $\left(\mathrm{P}_{2} \mathrm{O}_{5}\right)$; presumably Ca from calcite, $\mathrm{Mg}$ from biotite, $\mathrm{K}$ from feldspar, and $\mathrm{P}$ from apatite. Thus, the rock dust used in the experiment constituted a source of nutrients. Granulometric analysis showed that the majority of rock dust particles had a diameter of $0.15 \mathrm{~mm}$, which is an adequate size for soil fertilization purposes.

Genetics and Molecular Research 15 (4): gmr.15048729 


\section{Plant height and biomass production}

The data for plant height growth, characterized by the absence of inoculant and the presence of rock dust (S135RWI and S27RWI) revealed that Jatropha curcas L. was more efficient in the absorption and utilization of nutrients when they already existed or when they were supplied by the mineral residue in low quantities. The native microbiota associated with the plant may have played an important role in improving the availability of such nutrients in S135RWI and S27RWI by releasing organic acids or by producing plant-stimulating hormones, as also reported by Resende et al. (2011). However, the presence of PSB may have had an inadequate effect on plants, as observed especially for plants in SWRI, where the absence of rock dust was a negative factor for plant growth. In plants grown in soil that received higher quantities of rock dust, problems such as difficulty of aeration, soil compaction, and insolubility, previously observed by other authors (da Silva et al., 2008), combined with the effects of inoculation with PSB, may have influenced the unfavorable results for plant height in the treatments at the beginning of plant development. Among these factors, microbial inoculation may have exhibited a greater influence when the dosages of rock dust were small compared with the ones used in other studies, such as those by Knapik and Angelo (2007) or Prates et al. (2011), where the authors reported the possibility of soils being subject to compaction. Numerous soil properties, including soil texture and mineralogy, can influence microbial communities and plants (Heckman et al., 2009). However, as J. curcas L. growth in response to fertilization with rock dust has no standard precedents, the inadequate effects observed for this fertilization may result from the environmental, physical, and chemical conditions of the soil, or even from the reaction of the plant to this kind of fertilization. Although the PSB used in this study demonstrated good phosphate solubilization in vitro, performance variations in situ may have been reflected in plant height. Inadequate absorption of nutrients by the plant at the beginning of the growing period may arise from a lack of plant adaptation to the inoculum owing to competitive disadvantage or to dilatory bio-solubilization of phosphorus from the rock dust. Khan et al. (2007) showed that this may occur when using bacteria for seed inoculation or direct application to the soil. The inoculum may comprise different bacterial strains or may be produced by different associations with bacteria already existing in the soil, which may benefit plant growth and development, but it may also result in competition with the plant for nutrients (Vassileva et al., 2010; Richardson and Simpson, 2011). Consequently, bacterial strains from the inoculant may have competed with each other, with native microbiota, and with the plant, for phosphorus consumption, thereby inhibiting plant development at the beginning of the growing period. Within the rhizosphere, there is a demand for $\mathrm{P}$ among plants and microorganisms, with the latter being more competitive owing to their ability to reduce plant derivatives and their proximity to the root surface.

With regard to dry biomass production in the plants, the results indicated that there was little synthesis of reserve compounds for storage in stem and root structures, as reflected in the total weight of both plant organs in plants from SWRWI. This revealed a higher physiological efficiency in the plants, which were able to exploit a reduced nutrient supply for growth. The plant, along with soil microorganisms, may produce regulating hormones, such as cytokinins (Epstein and Bloom, 2006). These hormones move towards the growth spots in shoots, making these locations more efficient at acquiring the nutrient reserves demanded for growth. The processes of absorption, redistribution, and allocation of $\mathrm{P}$, and possibly other nutrients, were satisfactory, as probably reflected in the better values for biomass production.

Genetics and Molecular Research 15 (4): gmr.15048729 
For other treatments, dosages of rock dust higher than 13.5 and $27 \mathrm{~g}$ may have compromised nutrient absorption by the roots of $J$. curcas L. during the initial period of its development. Limitations of available $\mathrm{P}$ and other nutrients during the beginning of plant growth may result in restrictions in development, without the possibility of a later recovery, even with increasing nutrient availability (Pádua, 2012). Phosphorus is one of the key mineral constituents required for cellular activity; it is also the most limiting nutrient for biomass productivity of plants growing in tropical soils. The inadequate response of plants to some treatments, due to previously mentioned problems, may have occurred in the beginning of the development period, indicating difficulties in the transport of compounds from plant organs to plant drains, i.e., roots and stalks. This may have resulted in competition between drain and source, reflected in the low biomass production. Roots are responsible for gathering crucial reserve substances required for the development of $J$. curcas $\mathrm{L}$. Therefore, when the plant is cultivated in an environment that is unfavorable for its development, e.g., modified physical and chemical proprieties of the soil, detrimental effects are expected, such as reduction in biomass production, and impaired plant growth and distribution of compounds among plant organs.

In the present study, the native microbiota was probably more important for the growth of $J$. curcas L. with regard to dry biomass production. Bacteria with the ability to solubilize phosphates by producing organic acids or phosphatases may indirectly make nutrients available for plant absorption (Marschner et al., 2011). Bacteria from the native microbiota may be associated with plant adaptation, and their isolation for incorporation into a new inoculum must be considered. In contrast, given the results for biomass production when PSB constituted the inoculum, there was no evidence that these microorganisms are effective at promoting growth in $J$. curcas $\mathrm{L}$.

\section{DGGE analysis, dendrograms, and DNA sequencing}

The structure of bacterial communities was modified during the experiment over a short period, but few bacterial populations were detected by DGGE in either inoculated or noninoculated treatments, demonstrating a close interaction between some microbial populations and the plant. The absence of two bacterial populations, no longer observed 210 days into the experiment, suggests an absence of adaptation among some bacterial populations of native microbiota, and between these and the plant. The absent populations may have been selected or had reduced numbers of individuals within the population, which would not support competition for nutrients with other bacterial populations, and would be negatively influenced by the release of toxic substances from the plant (Dieng et al., 2014, 2015). Bacterial strains from the genus Bacillus were detected, confirming its constant presence in the rhizosphere of $J$. curcas L. Owing to the pronounced modification of the profile of bacterial communities after inoculation, the presence of a product containing phosphate as well as the probable successes in nutrient competition with other microorganism and with the plant may explain the dominance of PSB. A population of Bacillus atrophaeus SL13, one of the strains used in the inoculum, was present in the soils before inoculation. However, although bacteria from the genus Bacillus are able to promote plant growth (Gomes et al., 2011), the occurrence of this strain within the native microbiota as well as in the inoculum was probably related to the different effects on plant height and biomass production in J. curcas L. In plants from SWRWI, adapted to the soil and to the present microbiota, the strain may have contributed to the better results observed in plant growth, whereas in the treatments with inoculation it

Genetics and Molecular Research 15 (4): gmr.15048729 
may have competed for phosphate with other bacteria from the inoculum, jeopardizing plant development. However, the importance of the other three strains from the inoculum on the undesired effects on $J$. curcas L. growth may not be dismissed, because they were not detected when the plant had its best performance in biomass production under the influence of the native microbiota only. Conspicuous variability between gel bands with inoculated samples suggested that PSB were not negatively influenced by J. curcas L., with the opposite being most provable, thus reflecting inadequate plant growth. The most prominent bands in the DGGE profiles for regions V6-V8 of the 16S rDNA were identified by sequencing analysis as attributable to Bacillus, thereby demonstrating the significance of this bacterial genus in $J$. curcas $\mathrm{L}$. growth. A wide variety of microorganisms that are capable of solubilizing inorganic $\mathrm{P}$ were isolated from the soil, including those from the genera Actinomycetes, Pseudomonas, and Bacillus (Richardson and Simpson, 2011). Among these, the genus Bacillus is usually found in soils and is thought to include a great number of PSB species. Nevertheless, despite being a bacterial group that prevailed in the soil after inoculation, treatments with the inoculant did not increase plant height or biomass production in J. curcas L. As mentioned, these bacteria may have contended for nutrients in the soil, thus affecting plant growth. Without competition from the PSB, other bacteria and rhizosphere fungi from the native microbiota may have established a positive relationship with the plant.

A higher number of fungal communities were detected. The increases and decreases in the number of populations observed in some gel lines may indicate, as with the results from the primers for the $16 \mathrm{~S}$ rDNA, that fungal populations were influenced by the presence of rock dust or by the plant, showing negative or positive selection patterns. A negative interaction between plants and microbial communities was also observed by Bao et al. (2013). A greater number of fungus populations were detected among plants with the maximum growth in height and higher biomass production. Some fungal populations were associated with the phyla Ascomycota and Chytridiomycota. Among these, Ascomycota is presumed to exert the greatest influence on $J$. curcas L. growth, if the phylum is present in plants with the best growth in height. Dieng et al. (2014) observed the presence of the phylum Glomeromycota in the rhizosphere of $J$. curcas L. This shows that fungal diversity in the rhizosphere of $J$. curcas L. may change depending on the environmental characteristics. Thus, environmental factors, such as the phosphorus content of the soil, the plant species, or both, have a close relationship with the fungal populations detected.

Variations in microbial diversity, as observed in fungal communities and bacteria in the present study, may be associated with such factors as the plant species and the soil characteristics. This suggests the pursuit of equilibrium after modification of environmental conditions (Souza et al., 2012). There were variations in the structure of the bacterial communities in the soil, as observed by the authors of other studies accessing bacterial communities with primers for $16 \mathrm{~S}$ rDNA and 18S rDNA (Nakatani et al., 2011). However, modifications occurred rapidly in the present study. Modifications in the structure of the soil microbial community associated with J. curcas L. may have occurred because of: a) competition of bacterial species existing in the inoculant with native bacteria, evidenced by the predominance of the first group mentioned and revealed by DGGE; b) the interaction of some groups of microorganisms with the plant, which in turn may have increased the selection of other populations of microorganisms; and c) the modifications of physical and chemical properties of the soil, resulting from the rock dust and the biological activity of the microorganisms associated with organic matter content and/ or the availability of soil nutrients, such as phosphorus.

Genetics and Molecular Research 15 (4): gmr.15048729 
The plants in SWRWI produced the best biomass results, proving that the native soil microbiota promoted better growth in $J$. curcas L. The microbial populations detected by DGGE and identified by sequencing participated in the various activities of microorganisms in the rhizosphere, such as solubilization of available nutrients from the soil and/or production of phosphatase enzymes. This suggests that native microorganisms promote growth in $J$. curcas L. These microorganisms will be isolated, tested for specific growth-promoting activities, and used in new inoculum formulations to enhance the growth of $J$. curcas L. as well as other vegetal species.

\section{CONCLUSIONS}

$J$. curcas L. did not react positively to inoculation with PSB. Improvements in the quality of the inoculum must be considered to increase the interaction between the microorganisms and the plant, and between the plant and soil, especially in the initial growing period. Favorable results were obtained only for plant height, in plants that received only rock dust, and did not provide full evidence for the utilization of this mining reject as the only source of nutrients affording efficient growth of $J$. curcas L. The plant produced greater dry biomass when the rock dust was not used, with or without PSB, suggesting the relevance of the native microbiota in growth promotion. The isolation of native microorganisms and microbial activity assays will reveal the specific potential of bacteria and fungi to promote plant growth; such microorganisms will ultimately be employed in new and improved inocula.

\section{Conflicts of interest}

The authors declare no conflict of interest.

\section{ACKNOWLEDGMENTS}

Research supported by the Biotechnology Program CAPES/Fiocruz and by the State Universities (UNEB, UESC, UEFS) in the cities of Alagoinhas, Ilhéus, and Feira de Santana, respectively. We would like to thank Professor Dr. Rachel Passos Rezende from the Centro de Biotecnologia e Genética (CBG), UESC, Ilhéus, Bahia, for kindly granting permission to use the Laboratory of Microbiology and Genetics to perform the DGGE experiments, and Professor Luciano Vaz from UEFS, Feira de Santana, Bahia, for the preliminary statistical analysis. We are also grateful for funding from the Post-Graduation Program in Biotechnology from the State University of Feira de Santana, UEFS, Bahia, Brazil.

\section{REFERENCES}

Ahmad MF, Kennedy IR, Choudhury ATMA, Kecskés ML, et al. (2008). Phosphorus adsorption in some Australian soils and influence of bacteria on the desorption of phosphorus. Commun. Soil Sci. Plant Anal. 39: 1269-1294. http:// dx.doi.org/10.1080/00103620802003963

Altschul SF, Gish W, Miller W, Myers EW, et al. (1990). Basic local alignment search tool. J. Mol. Biol. 215: 403-410. http://dx.doi.org/10.1016/S0022-2836(05)80360-2

Bao Z, Matsushita Y, Morimoto S, Hoshino YT, et al. (2013). Decrease in fungal biodiversity along an available phosphorous gradient in arable Andosol soils in Japan. Can. J. Microbiol. 59: 368-373. http://dx.doi.org/10.1139/ cjm-2012-0612

Genetics and Molecular Research 15 (4): gmr.15048729 
Broz AK, Manter DK and Vivanco JM (2007). Soil fungal abundance and diversity: another victim of the invasive plant Centaurea maculosa. ISME J. 1: 763-765. http://dx.doi.org/10.1038/ismej.2007.81

da Silva EA, Rodrigues Cassiolato AM, Maltoni KL and Scabora MH (2008). Effects of ground basalt and organic residues on the chemical and microbiological aspects on bare subsoil and on the growth of Astronium fraxinifolium Schott. Rev. Arvore 32: 323-333.

de Arruda FP, Beltrão NE de M, de Andrade AP, Pereira WE, et al. (2004). Cultivation of Jatropha (Jatropha curcas L.) as an alternative to the semi-arid Northeast. Ver. Bras. Oleaginosas Fibrosas 8: 789-799.

Dias DCFS (2007). Jatropha cultivation (Jatropha curcas L.) for fuel oil production. Viçosa.

Dias LA, Missio RF and Dias DC (2012). Antiquity, botany, origin and domestication of Jatropha curcas (Euphorbiaceae), a plant species with potential for biodiesel production. Genet. Mol. Res. 11: 2719-2728. http://dx.doi.org/10.4238/2012.June.25.6

Dieng A, Ndoye I, Duponnois R and Baudoin E (2014). Effects of Jatropha curcas L. plantation on soil bacterial and fungal communities. Soil Biol. Biochem. 72: 105-115.

Dieng A, Duponnois R, Ndoye I and Baudoin E (2015). Cultivation of Jatropha curcas L. leads to pronounced mycorrhizal community differences. Soil Biol. Biochem. 89: 1-11. http://dx.doi.org/10.1016/j.soilbio.2015.06.019

Epstein E and Bloom AJ (2006). Mineral nutrition of plants: principles and perspectives. 2a. ed. Planta, Londrina, 403.

Freitas RG, Missio RF, Matos FS, Resende MD, et al. (2011). Genetic evaluation of Jatropha curcas: an important oilseed for biodiesel production. Genet. Mol. Res. 10: 1490-1498. http://dx.doi.org/10.4238/vol10-3gmr1146

Gomes EA, Paiva CA de O, Dias FES, dos Santos FC, et al. (2011). Effect of phosphate solubilizing bacteria on the growth of pearl millet (Pennisetum glaucum) fertilized with rock phosphate. Boletim de Pesquisa e Desenvolvimento, 43. Embrapa Milho e Sorgo, Sete Lagoas, MG, Brasil.

Grayston SJ, Campbell CD, Bardgett RD, Mawdsley JL, et al. (2004). Assessing shifts in microbial community structure across a range of grasslands differing in management intensity using CLPP, PLFA and community DNA techniques. Appl. Soil Ecol. 25: 63-84. http://dx.doi.org/10.1016/S0929-1393(03)00098-2

Heckman K, Welty-Bernard A, Rasmussen C and Schwartz E (2009). Geologic controls of soil carbon cycling and microbial dynamics in temperate conifer forests. Chem. Geol. 267: 12-23. http://dx.doi.org/10.1016/j.chemgeo.2009.01.004

Heuer H and Smala K (1997). Application of denaturating gradient gel electrophoresis (DGGE) and temperature gradient gel epectrophoresis (TGGE) for studying soil microbial communities. In: Modern Soil Microbiology (van Elsas JD, Wellington EMH and Trevors JT, eds.). Marcel Dekker, New York, 353-373.

Khan MS, Zaidi A and Wani PA (2007). Role of phosphate-solubilizing micro-organisms in sustainable agriculture - A review. Agron. Sustain. Dev. 27: 29-43. http://dx.doi.org/10.1051/agro:2006011

Khan MS, Zaidi A, Ahemad M, Oves M, et al. (2010). Plant growth promotion by phosphate solubilizing fungi - current perspective. Arch. Agron. Soil Sci. 56: 73-98. http://dx.doi.org/10.1080/03650340902806469

Knapik JG and Angelo AC (2007). Basalt powder and manure horse in the production of Prunus seedlings sellowii Koehne. Floresta, Curitiba.

Kpomblekou-A K and Tabatabai MA (2003). Effect of low-molecular weight organic acids on phosphorus release and phytoavailability of phosphorus in phosphate rocks added to soils. Agric. Ecosyst. Environ. 100: 275-284. http:// dx.doi.org/10.1016/S0167-8809(03)00185-3

Lapido-Loureiro FEV and Nascimento M (2009). Importance and function of fertilizers in sustainable and competitive agriculture. Fertilizer: agribusiness and sustainability. CETEM/Petrobrás, Rio de Janeiro, 81-132.

Legendre L and Legendre P (1983). Numerical Ecology. Elsevier, New York.

Marchante E, Kjøller A, Struwe S and Freitas H (2008). Invasive Acacia longifolia induce changes in the microbial catabolic diversity of sand dunes. Soil Biol. Biochem. 40: 2563-2568. http://dx.doi.org/10.1016/j.soilbio.2008.06.017

Marschner P, Crowley D and Rengel Z (2011). Rhizosphere interactions between microorganisms and plants govern iron and phosphorus acquisition along the root axis - model and research methods. Soil Biol. Biochem. 43: 883-894. http:// dx.doi.org/10.1016/j.soilbio.2011.01.005

Muyzer G, de Waal EC and Uitterlinden AG (1993). Profiling of complex microbial populations by denaturing gradient gel electrophoresis analysis of polymerase chain reaction-amplified genes coding for 16S rRNA. Appl. Environ. Microbiol. 59: 695-700.

Nakatani AS, Martines AM, Nogueira MA, Fagotti DSL, et al. (2011). Changes in the genetic structure of bacteria and microbial activity in an agricultural soil amended with tannery sludge. Soil Biol. Biochem. 43: 106-114. http://dx.doi. org/10.1016/j.soilbio.2010.09.019

Nautiyal CS (1999). An efficient microbiological growth medium for screening phosphate solubilizing microorganisms. FEMS Microbiol. Lett. 170: 265-270. http://dx.doi.org/10.1111/j.1574-6968.1999.tb13383.x

O’Sullivan DJ and O'Gara F (1992). Traits of fluorescent Pseudomonas spp. involved in suppression of plant root pathogens. Microbiol. Rev. 56: 662-676.

Genetics and Molecular Research 15 (4): gmr.15048729 
Pádua EJ (2012). Stonemeal as complementary fertilizer for oilseed crops. Universidade de Lavras, MG.

Paul D and Lade H (2014). Plant-growth-promoting rhizobacteria to improve crop growth in saline soils: a review. Agron. Sustain. Dev. 34: 737-752. http://dx.doi.org/10.1007/s13593-014-0233-6

Prates FBS, Lucas CSG, Sampaio RA, Brandão Jr DS, et al. (2011). Growth of Jatropha seedlings in response to fertilization with superphosphate and rock dust. Ver. Ciênc. Agron. 43: 207-213. http://dx.doi.org/10.1590/S1806$\underline{66902012000200001}$

Resende AV, Hickmann C, Batista RO, Marriel IE, et al. (2011). Avaliação preliminar de um processo de compostagem visando a solubilização e agregação de valor a agrominerais como fontes de fósforo e potássio. Boletim de Pesquisa e Desenvolvimento. EMBRAPA.

Richardson AE and Simpson RJ (2011). Soil microorganisms mediating phosphorus availability update on microbial phosphorus. Plant Physiol. 156: 989-996. http://dx.doi.org/10.1104/pp.111.175448

Rodríguez H and Fraga R (1999). Phosphate solubilizing bacteria and their role in plant growth promotion. Biotechnol. Adv. 17: 319-339. http://dx.doi.org/10.1016/S0734-9750(99)00014-2

Santos AFJ and Esposito E (2014). Interaction between microorganisms and socio-environmental biotechnology. In: Public policies: studies and cases (Panhoca I and Bonini LMM, eds.). Org. Ciancarullo, T.I., Ícone, São Paulo.

Seesuriyachan P, Kuntiya A, Hanmoungjai P, Techapun C, et al. (2012). Optimization of exopolysaccharide overproduction by Lactobacillus confusus in solid state fermentation under high salinity stress. Biosci. Biotechnol. Biochem. 76: $912-$ 917. http://dx.doi.org/10.1271/bbb.110905

Souza GS, Schelemman F, Alencar PM, Lopes AAC, et al. (2012). Estrutura metabólica e genética de comunidades bacterianas em solo de cerrado sob diferentes manejos. Pesq. Agrop. Bras. 47: 267-276.

Tsavkelova EA, Cherdyntseva TA and Netrusov AI (2005). Auxin production by bacteria associated with orchid roots. Mikrobiologiia 74: 55-62.

Vassileva M, Serrano M, Bravo V, Jurado E, et al. (2010). Multifunctional properties of phosphate-solubilizing microorganisms grown on agro-industrial wastes in fermentation and soil conditions. Appl. Microbiol. Biotechnol. 85: 1287-1299. http://dx.doi.org/10.1007/s00253-009-2366-0

Yang J, Kloepper JW and Ryu CM (2009). Rhizosphere bacteria help plants tolerate abiotic stress. Trends Plant Sci. 14: 1-4. http://dx.doi.org/10.1016/j.tplants.2008.10.004

\section{Supplementary material}

Table S1. Expression of mean height $(\mathrm{cm})$ of Jatropha curcas L. plants for treatments SWRWI $(0 \mathrm{~g}$ rock dust, without inoculum) and S81RWI (81 g rock dust, without inoculum).

Table S2. Expression of mean height $(\mathrm{cm})$ of Jatropha curcas L. plants for treatments SWRWI $(0 \%$ rock dust, without inoculum) and SWRI ( $0 \%$ rock dust, with inoculum).

Table S3. Expression of mean height $(\mathrm{cm})$ of Jatropha curcas L. plants for treatments SWRWI $(0 \%$ rock dust, without inoculum) and S81RI (81 g rock dust, with inoculum).

Genetics and Molecular Research 15 (4): gmr.15048729 